\title{
Electric Power System Fault Analysis
}

\author{
DA YOUNG TU'UAU, TIMAIMA MARICA, and MANSOUR H. ASSAF \\ School of Engineering and Physics \\ University of the South Pacific \\ Laucala Campus, Suva \\ FIJI ISLANDS
}

\begin{abstract}
Fault analysis is an important aspect in the successful operation of a power utility grid. The occurrence of faults in the system is not avoidable as causes of faults are not particularly one but of many with different causes and nature. It is one of the most important as well as it one of the most complex tasks in power engineering. The studies and discovery of faults in electric power systems is essential in ensuring the consistency and the stability if the power grid. Another importance of carrying out fault analysis gives a fair idea of the voltages and the current magnitudes under faulty conditions for different scenarios. This is helpful in the design of protection devices such as fuses, circuit breaker ratings, over current protection relays and other devices that are used for the protection of the system. Protection devices are important features of the power system grid mainly because their role in saving equipment and also human lives. In this paper, we investigate and analyze the behavior of electric power systems under fault conditions and then evaluate various practical scenarios.
\end{abstract}

Key-Words: - Electric power systems, geographic information system, electronic transient, analysis program, synchronous generator.

Received: October 23, 2019 . Revised: February 1, 2020. Accepted: February 21, 2020. Published: March 6, 2020.

\section{Introduction}

Electric power system is a complicated network that consists of components that produces and delivers electricity to consumers. The electrical power system is made up of mainly six networks which are generation, transformers, transmission lines, substations, distribution lines and distribution transformers. The production and the transmission of electricity is moderately efficient and inexpensive, although electricity is not easily stored compared to other forms of energy, thus electricity is produced based on demand [1]. The load consumption increasing over the years yields a higher demand in electricity and its production. The distribution of the supplied power is uneven and the varying load demand is leading to high power delivery capacity [2].

For the period of operating situations, current will flow through all the elements of the electrical power system within the pre-designed values which are appropriate to the elements' ratings. The power system values can be calculated by analyzing system voltages and currents under both normal and abnormal cases. Due to the variations in the system and complications between the networks as well as natural events, faults within the system are always likely to occur. Fault is defined as a large flow of current in an inadequate path that causes equipment damage leading to a limited power supply or it could endanger lives.

To prevent such events, the power system analysis was introduced. Power system analysis is an important consideration when it comes into power system planning, equipment selection as well as reliability assessments. This is a process of evaluating the system voltages and currents under different cases to determine safety precautions and protections not just for the system but also the lives of the working personnel and the general public. The study of fault analysis can determine protection settings to design components such fuses, circuit breakers and relays varying in sizes and types depending on analysis and design.

The severity of the faults are dependent upon the short circuit location as well as the path of the fault current, system impedance and its voltage levels [3]. The main purpose of a power system is to supply electricity to consumers, thus having a fault in the system is an interruption to the supply and possibly and endangerment to the lives involved. This paper 
analyze different types of faults and its possible causes on a power grid system particularly Samoa as a case study. In the next section we present a brief literature review.

\section{Background}

The need for a reliable and a stabilized electric grid is one of the main aspects of power system analysis. It is not possible to design a power system grid without knowing the risks and the consequences of the system in normal and abnormal conditions. In any transmission or distribution systems, all the equipment are intended to carry specific amount of current. Any current value higher than the pre-set of pre-designed values could damage the equipment as well as disturbing the balance of the system. The occurrence of faults is unpredictable and the behavior of the system is also dependent on how severe the fault is.

Electricity is generated, transmitted and distributed through networks of power systems which are interconnected and associated together to deliver power. To generate and deliver power successfully, the electric power systems contain these mechanisms, generation, transformers, transmission lines, substations, distributions lines and distribution transformers. The generation of power occurs in a power plant where it consists of apparatuses and machines which produce energy. The transformers are used to raised and lower the voltage of the generated power energy to suit its corresponding environments. For example, the generated energy voltage is raised before it is transmitted and then lowered before it is distributed and it is usually carried out in a substation. The reason for transmitting high voltages and low current is to basically reduce heat and power losses that arise through the process [4].

The main objective of power systems is to basically sustain power supply throughout. In the normal operations of power systems, the current flows through all the elements but within the range of the pre-designed values that suits the elements' ratings. On the other hand, there are some events that occur which could not be prevented such as weather conditions, accidents, natural disasters and other unpredictable causes that disrupts the operation of the power systems causing undesirable outputs. Events that cause disruptions to the system are known as faults.

There are different types of faults and it is usually classified by its nature and cause, but in definition, a fault is large flow of current through a wrong pathway. Faults can occur in different locations and it could cause a lot of damages and failures as well as endangering lives that are present during a fault occurrence depending on how severe the fault is [3]. For the reason that these faults are dangerous and life threatening, fault analysis was developed.

Performing fault analysis of a power system can provide information that leads to designs and selections of protection devices such as switches, relay settings, circuit breaker ratings, fuses and system stability operation which are used to isolate and protect the systems in case of faults. This study is generally carried out in per-unit quantities as it gives solutions which are consistent of voltage differences and power ratings as well as its operation on unity order [5].

Faults occur when the system performance is affected by a problem whether by a natural disaster, weather conditions, and accidents or just due to some equipment failures. The steady state operating mode of a power system is a three-phase AC but in term of faults, this operation is disrupted. The two most known faults that occur in the transmission networks are known as balanced faults and unbalanced faults. Faults are also categorized as series, shunt and simultaneous according to its nature [3], [6]. The analysis of fault conditions for power systems are important that is makes a difference in order to guarantee the best possible outcome results of the carried analysis. This paper focuses mainly on the analysis of shunt and simultaneous faults. Next we describe different types of faults that may occur. 


\section{Types of Faults}

In general, the two most known faults that occur in the transmission networks are known as balanced faults (symmetrical) and unbalanced faults (unsymmetrical). Faults can be classified as series or shunt.

\subsection{Series Faults}

These types of faults occur when a conductor is opened with unbalanced series impedance conditions of the line [3]. The examples of this type of fault could be when the system has one or two broken lines or when the impedance is injected in one or two lines. In reality or in other words real life scenario, the fault takes place when the circuit breaker takes control of the lines without opening all the three phases thus allowing one or two of the phases to be opened while the other is closed [6]. Series faults are classified by the increase in the voltage and the frequency with a drop in the current of the faulted phases.

\subsection{Shunt Faults}

Shunt faults are the most common type of faults that occur in power systems, which involve power conductors, a conductor to ground or just a short circuit between the conductors [3]. Shunt faults causes increasing current and decreasing voltage and frequency. It is classified in to four categories as follows:

\subsubsection{Line-to-Ground (LG) Fault}

About $70 \%$ of fault occurrences are line to ground faults [7], which is caused when one phase of any transmission lines finds a connection with the ground.

\subsubsection{Line-to-Line (LL) Fault}

When one phase is in contact with another phase, usually caused by a cyclones or strong winds. About $15 \%$ of transmissions faults are found to be line to line faults [7].

\subsubsection{Double Line-to-Ground (LL-G) Fault}

Usually caused by falling trees, a double line to ground fault occurs when two phases are in contact or become connected the ground, similar to the line to ground but instead of one line, now it is two lines. About $10 \%$ of the faults are caused by double line to ground [7].

\subsubsection{Three Phase Fault}

Three phase faults are usually occurred due to equipment failure, falling tower or line breaking due to over loads. This type of faults does not quite happen often and thus only about $5 \%$ of faults are caused by this [7].

Common causes of faults are:

- Heavy Winds

- Cyclones

- Falling Trees

- Car Accidents (Car collision to electric poles)

- Lightning

- Aircraft collision with lines

- Birds and other small animals

- Line breakage due to excessive loadings

The first three types of faults represents unbalanced operating situations which refers to one or two phases thus it is called unsymmetrical faults. The last type of fault involves all three phases thus referred to balanced or symmetrical faults.

The events of faults depending on its severity could lead to fire outbreak, property and equipment damages, and loss of life and destruction of the power systems networks. Faults could also cut the supply of other areas which are beyond fault points in transmission and distribution networks which could lead make the whole system blackout. If at this situation, damages may go as far as hindering services such as industries and commercial buildings such as offices and schools. This could lead to under developments of economic of a country. Therefore it is very important to determine the values of system currents and voltages under faulted conditions. The proposed system is described next.

\section{System Modeling}

The main aim of the proposed work is to collect and analyze real industrial data, and develop a system capable of detecting and locating faults in an electrical power system. The development of the proposed system was done ETAP. Figure 1 shows the development phases of the proposed system. 


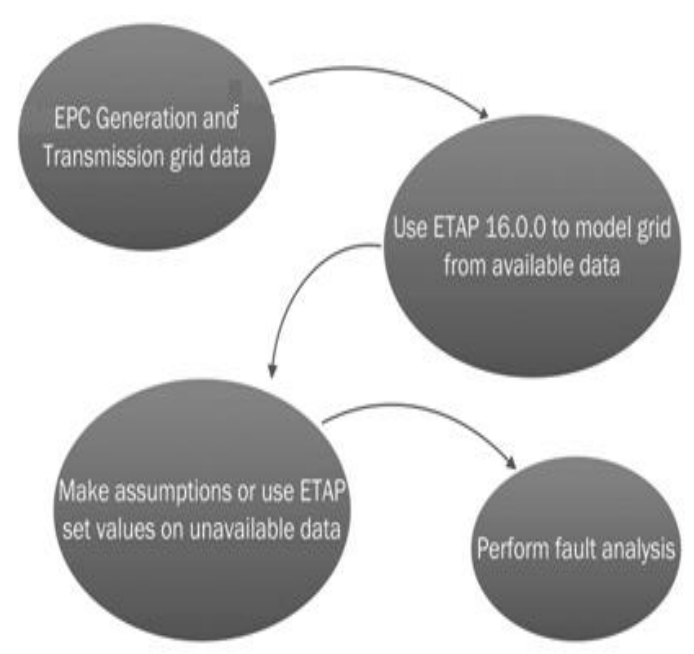

Fig. 1 System Overview

Information and data is collected first, followed by a grid model is developed in ETAP software, assumptions are made, then fault analysis is performed.

Figure 2 shown below; presents a sample of what the system is basically like. The first part is the production or the generation side, where the electric power energy is produced and generated. This power energy is then raised up to higher voltages and transmitted to substation where the voltage is lowered again before distributing it to the consumers. The EPC power grid does not have a pure transmission system as there are only two generating stations and one substation, thus the $33 \mathrm{kV}$ line is classified as transmission network together with the Solar Farms which are under the $22 \mathrm{kV}$ lines. The distributed voltage which is $22 \mathrm{kV}$ is stepped down again to $415 \mathrm{~V}$ for three phase loads and $240 \mathrm{~V}$ for single phase loads.

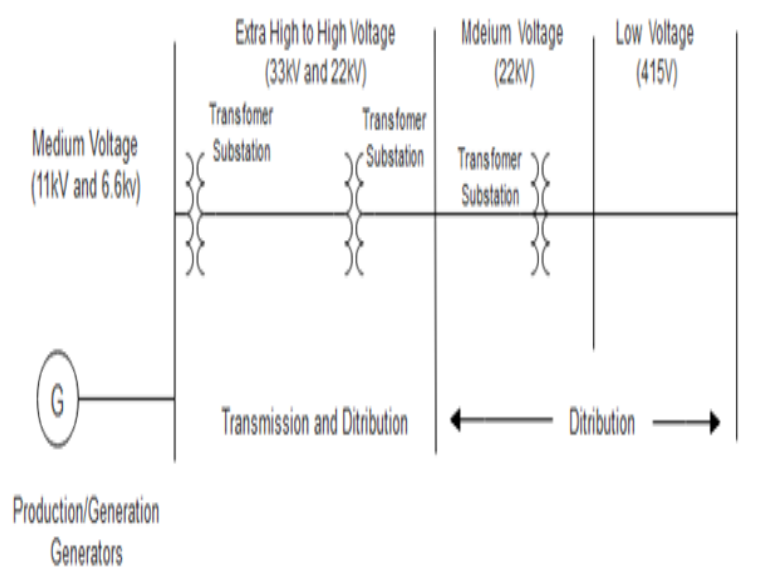

Fig. 2 Design Overview
Figure 3 shows the symmetrical component of a fault current in compliance with IEC 60909 standard which defines an internationally recognized method for the fault calculations. Applying the IEC standards yields fault levels based on the voltage factors which are normally calculated at the maximum current which causes maximum thermal and electromagnetic effects on the equipment, this is use to determine the equipment rating and at the minimum current which is used to design the settings for the protection devices [10]. There are three periods of time or phases as follows:

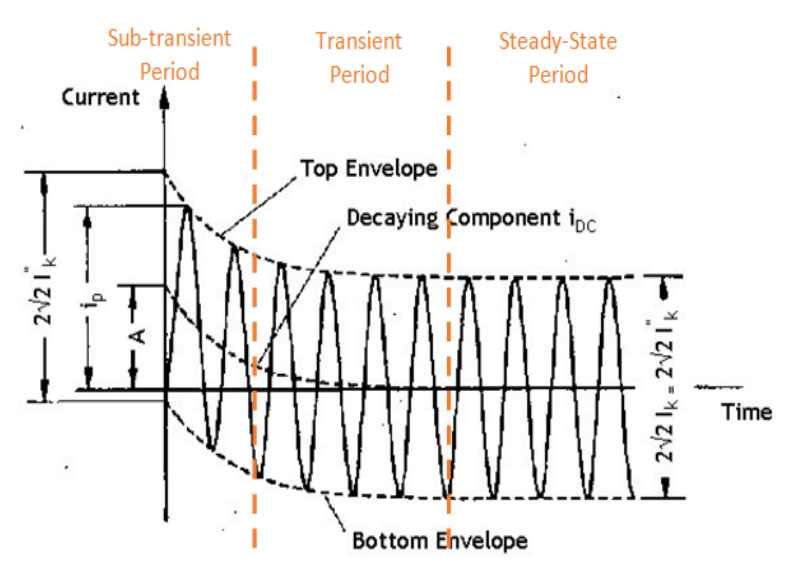

Fig. 3 IEC 60909 Fault Current [9]

Where:

I" ${ }_{k}$ is the initial symmetrical short circuit current $I_{p}$ is the peak short-circuit current

$\mathrm{I}_{\mathrm{k}}$ is the steady state short-circuit current $i_{D C}$ is the decaying DC component of short-circuit current

$A$ is the initial value of $i_{D C}$

Sub-transient period - these are the first couple of cycles after the fault where the AC current is very high and falls very rapidly:

$$
\begin{aligned}
& I^{\prime \prime}=\frac{E_{A}}{X^{\prime \prime}} \\
& E^{\prime \prime}=\left[\left(V+X_{d}^{\prime} I \sin \varnothing\right)^{2}\left(X_{d}^{\prime \prime} I \cos \varnothing\right)^{2}\right]^{1 / 2}
\end{aligned}
$$

Transient period - current decreases at a slower rate going to steady state:

$$
\begin{aligned}
& I^{\prime}=\frac{E_{A}}{X^{\prime}} \\
& E^{\prime}=\left[\left(V+X_{d}^{\prime} I \sin \emptyset\right)^{2}\left(X_{d}^{\prime \prime} I \cos \varnothing\right)^{2}\right]^{1 / 2}
\end{aligned}
$$

Steady State Period - this is when the current reaches its steady value or its steady state condition:

$$
I_{s s}=\frac{E_{A}}{X_{S}}
$$




$$
E=\left[\left(V X_{d} I \sin \emptyset\right)^{2}\left(X_{d} I \cos \emptyset\right)^{2}\right]^{1 / 2}
$$

The AC current that flows in the generator during the sub-transient period is known as the subtransient current which is denoted by I' and defined in equation (1). The time constant for the subtransient current can be found from the slope of the fault current graph. This current is very high that it is almost ten times of the steady state fault current [11]. The transient period defines the AC current as transient current which is denoted by I' and is defined in equation (3). The final period or the steady state obtains the steady state current which is defined in equation (5). The equations given by (2), (4), and (6) are used to calculate the EMF of each period, sub-transient, transient and steady state respectively.

\subsection{Three-Phase Fault}

The configuration of the three phase fault is shown in figure 4. All the three phases are shorted together in a three phase fault.

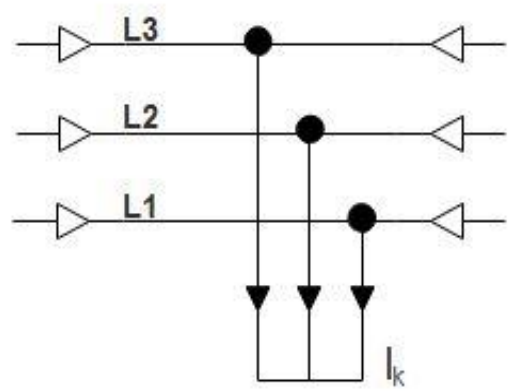

Fig. 4 Three Phase Fault Configuration

Analysis of the three phase fault is to find the fault current at any point in the network by summing the impedances of the network between the source of supply and the point where the fault takes place [10]. In order to find the fault current $\mathrm{Ik}$, the nominal voltage is divided by the sum of the impedances $\mathrm{Z}$.

$$
I_{k}=\frac{V n}{Z}
$$

The three phase fault is a symmetrical fault which occurs less frequently yet the most dangerous [3]. Since the phases or the lines in this fault are all balanced, there is zero current on the neutral phase and the sum of the three phases are equal to zero with the phase voltages all the equal [12].

\subsection{Double-Line to Ground Fault}

Figure 5 show the double-Line to ground configuration.

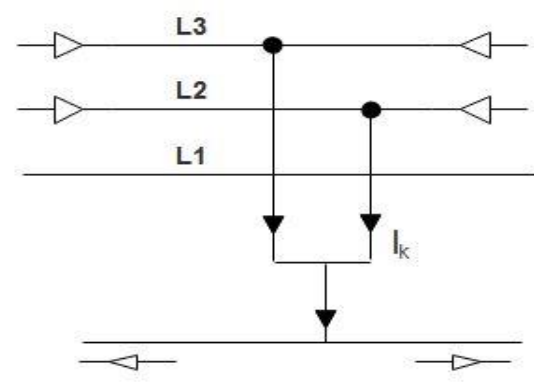

Fig. 5 Double-line to ground fault

$$
\begin{aligned}
& \boldsymbol{I}_{\boldsymbol{L} 1}=\mathbf{0} \\
& \boldsymbol{V}_{\boldsymbol{L} \mathbf{3}}=\left(\boldsymbol{I}_{\boldsymbol{L} 3}+\boldsymbol{I}_{\boldsymbol{L} \mathbf{2}}\right) \boldsymbol{Z} \\
& \boldsymbol{V}_{\boldsymbol{L} \mathbf{3}}=\boldsymbol{V}_{\boldsymbol{L} \mathbf{2}}
\end{aligned}
$$

\subsection{Line to Line Fault}

The line to line or sometimes known as the phase to phase fault happens when the one line to another line or two phases are connected together causing a short circuit. The fault current is calculated from dividing the voltage by the sum of impedances.

$$
\begin{aligned}
& I_{L 3}=0 \\
& I_{L 2}=-I_{L 1} \\
& I_{k}=\frac{\sqrt{3}}{2} \frac{V_{L N}}{Z}
\end{aligned}
$$

As shown in figure 6 , the line to line fault occurring at line 2 (L2) and line 1 (L1) which causes an open circuit at line 3 (L3) making it equal to 0 as shown by equation (11) as it carries no current.

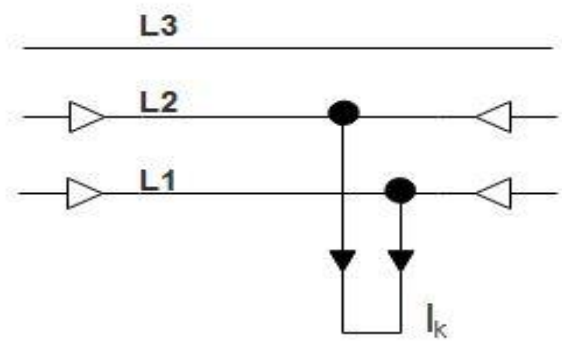

Fig. 6 Line to line fault configuration

Although, the fault current in line 2 (L2) and line 1 (L1) given by equation (12) shows that the positive sequence components of the current in line 2 (L2) is opposing the negative sequence for the component of line 1 (L1) current. 


\subsection{Line to Ground Fault}

The line to ground or the phase to ground is fault caused when one line or one phase becomes in contact with the ground. The Figure 7 shows a basic configuration of this fault. This fault is also known as the earth fault. The value for this fault is obtained from summing the earth fault impedance of the supply source and return path.

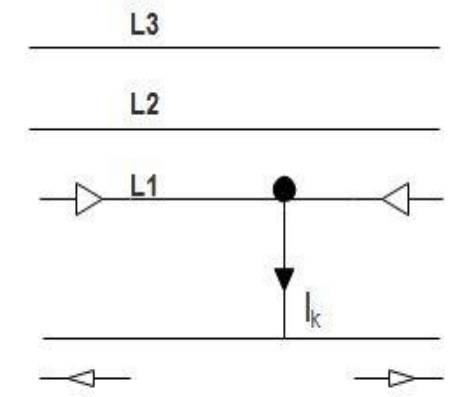

Fig. 7 Line to ground fault configuration

$$
\begin{aligned}
& I_{L 2}=I_{L 2}=0 \\
& I_{k}=\frac{V_{L N}}{Z+Z_{0}} \\
& V_{L 1}=Z I_{k}
\end{aligned}
$$

The line 3 (L3) and line 2 (L2) are open circuited, thus carries no current which given by equation (14). The fault current is located on line 1 (L1) and thus given by the equation (15). In the next section we present the implementation results.

\section{Implementation Results}

The proposed system was implemented in ETAP 16.0.0 (Electrical Transient and Analysis Program) that provides a uniform user interface for modeling design, analysis, and simulation of the EPC power grid faults. ETAP is electrical power system analysis and operation software with features such as simulations, optimization, monitoring, control and automation of electrical power systems [13]. It offers the power systems enterprise solutions that extent from modeling to operation.

To analyze practical Electrical Power System (EPC) faults, we used data from Samoa islands in the South Pacific. The utility grid was modeled in ETAP according to the parameters provided by the EPC Samoa, as viewed in figure 8.

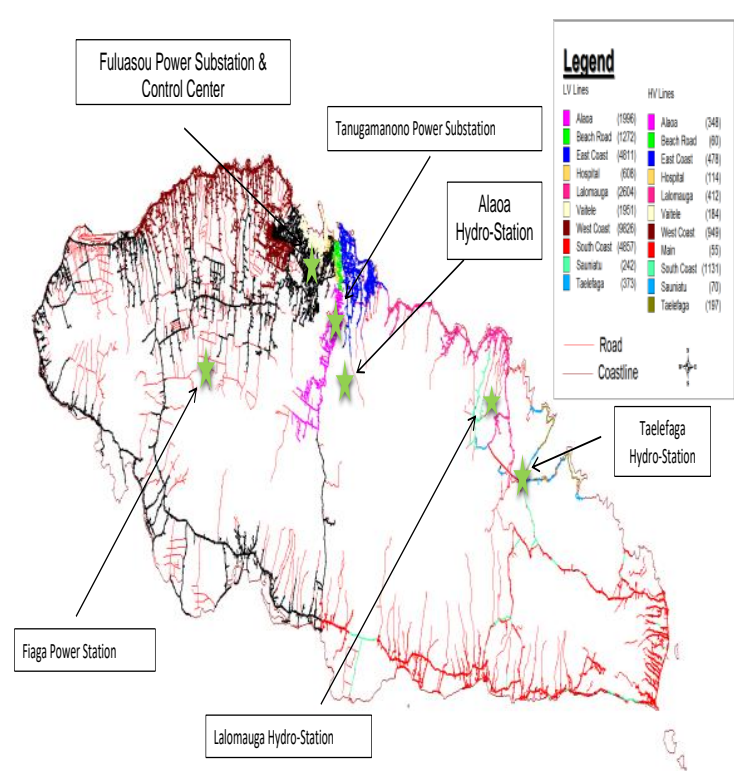

Fig. 8 map of Upolu, Samoa indicating feeder lines [8]

EPC Samoa utility grid comprises four utility stations:

- Fiaga Diesel Power Station

- Fuluasou Substation which functions as the National Control Center

- Tanugamanono Substation

- Lalomauga \& Taelefaga Hydro Stations

Tanugamanono substation controls FOF and Alaoa hydro stations. The map of the feeder lines in Upolu, Samoa (figure 8) was obtained from the Samoa EPC GIS using the Map Professional software licensed under Samoa EPC in 2014.

Figure 9 shows the ETAP model - EPC Upolu, Samoa.

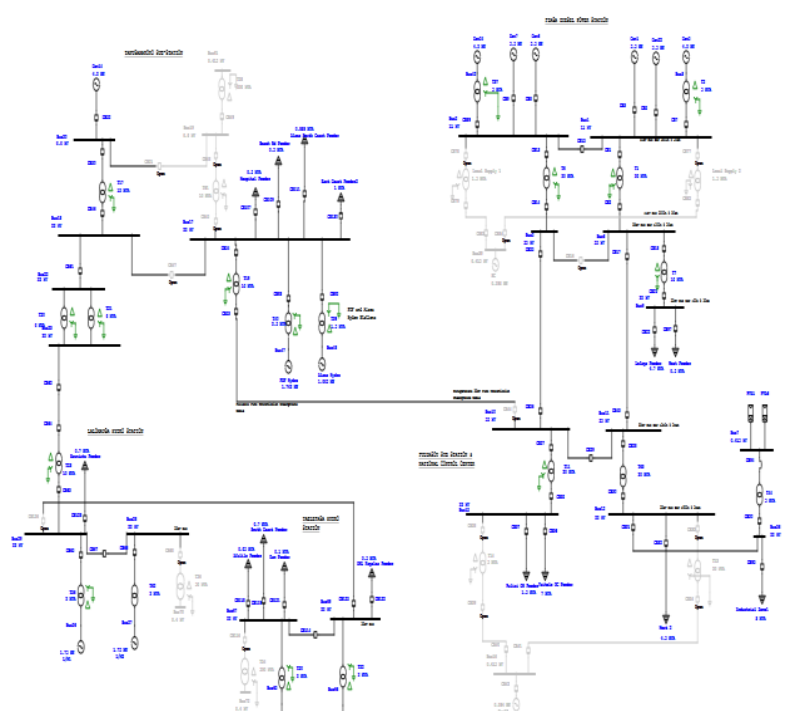

Fig. 9 EPC Upolu, Samoa 
Descriptions of stations involved in the regulation of electricity in Upolu are presented below. Diesel and Hydro are the major stations in the system while the PV system supports one feeder. Fiaga substation comprised of diesel generators, buses, transformers and feeders as shown in table 1 .

Table 1 Fiaga Substation Equipment

\begin{tabular}{|c|c|c|c|}
\hline & $\begin{array}{l}\text { Existing } \\
\text { Label }\end{array}$ & $\begin{array}{l}\text { ETAP } \\
\text { Label }\end{array}$ & Rating \\
\hline \multirow[t]{7}{*}{ Generators } & No.7B & Gen24 & $6.6 \mathrm{kV}, 4.2 \mathrm{MW}$ \\
\hline & No.1 & Gen7 & $11 \mathrm{kV}, 5.5 \mathrm{MW}$ \\
\hline & No. 2 & Gen6 & $11 \mathrm{kV}, 5.5 \mathrm{MW}$ \\
\hline & No.3 & Gen1 & $11 \mathrm{kV}, 5.5 \mathrm{MW}$ \\
\hline & No. 4 & Gen 22 & $11 \mathrm{kV}, 5.5 \mathrm{MW}$ \\
\hline & No.9A & Gen5 & $6.6 \mathrm{kV}, 4.2 \mathrm{MW}$ \\
\hline & SG & SG & $415 \mathrm{~V}, 350 \mathrm{kVA}$ \\
\hline \multirow[t]{4}{*}{ Buses } & $11 \mathrm{kV}$ & $11 \mathrm{kV}$ & $2500 \mathrm{~A}$ at $30 \mathrm{kA}$ \\
\hline & $415 \mathrm{~V}$ & $415 \mathrm{~V}$ & $2000 \mathrm{~A}$ at $30 \mathrm{kA}$ \\
\hline & $33 \mathrm{kV}$ & $33 \mathrm{kV}$ & $1000 \mathrm{~A}$ at $20 \mathrm{kA}$ \\
\hline & $22 \mathrm{kVr}$ & $22 \mathrm{kV}$ & $400 \mathrm{~A}$ at $20 \mathrm{kA}$ \\
\hline \multirow[t]{7}{*}{ Transformers } & No.7B Tx & $\mathrm{T} 37$ & 5MVA, YNd11 \\
\hline & No. 9A Tx & $\mathrm{T} 2$ & 5MVA, YNd11 \\
\hline & $\mathrm{Tx} 1$ & $\mathrm{~T} 6$ & $\begin{array}{l}\text { 15/20MVA, 11/33kV, } \\
\text { YNd11 }\end{array}$ \\
\hline & $\mathrm{Tx} 2$ & $\mathrm{~T} 1$ & $\begin{array}{l}\text { 15/20MVA,11/33kV, } \\
\text { YNd11 }\end{array}$ \\
\hline & $\begin{array}{l}\text { Local } \\
\text { Supply } 1\end{array}$ & $\begin{array}{l}\text { Local } \\
\text { Supply } 1\end{array}$ & $\begin{array}{l}\text { 1.5MVA, } 11 / 0.415 \mathrm{kV}, \\
\text { Dyn11 }\end{array}$ \\
\hline & $\begin{array}{l}\text { Local } \\
\text { Supply } 2\end{array}$ & $\begin{array}{l}\text { Local } \\
\text { Supply } 2\end{array}$ & $\begin{array}{l}\text { 1.5MVA, } 11 / 0.415 \mathrm{kV}, \\
\text { Dyn11 }\end{array}$ \\
\hline & $\begin{array}{ll}\text { Auto } & \mathrm{Tx} \\
\text { No.1 } & \end{array}$ & $\mathrm{T} 7$ & $10 \mathrm{MVA}, 33 / 22 \mathrm{kV}$ \\
\hline \multirow[t]{2}{*}{ Feeders } & Lefaga & Lefaga & 4.7MVA \\
\hline & West & West & $0.5 \mathrm{MVA}$ \\
\hline
\end{tabular}

The $33 \mathrm{kV}$ transmission lines connect to the $33 \mathrm{kV}$ Bus Bar at Fuluasou Substation. Regular transformers were used with autotransformer specifications. The SG generator is used for auxiliary power.

Fuluasou Substation encompassed auxiliary generator, buses, transformers and feeders. The PV system assists in supplying the Industrial Zone1 Feeder. Power is supplied by the diesel generators from the Fiaga and hydro power from Tanugamanono substation. Tanugamanono Substation mainly comprised of hydro station, transformers, autotransformers, feeders and buses. In addition, local power supply is available for the station via two transformers. Lalomauga and Taelefaga hydro stations are connected through $22 \mathrm{kV}$ transmission tie-line with all but one feeder connected from Taelefaga station.

All bus bars, generators, feeders and transformers have circuit breakers for protective measures. Table 2 shows protection setting for all feeders.

Table 2 Protection setting for all feeders as of May

\begin{tabular}{|l|c|c|}
\hline Feeders & $\begin{array}{l}\text { Overcurrent } \\
\text { Setting (A) }\end{array}$ & $\begin{array}{l}\text { Earth Fault } \\
\text { Setting (A) }\end{array}$ \\
\hline South Coast & 90 & 12.0 \\
\hline Fagaloa & 60 & 3.0 \\
\hline Tae-Lalo 22kV tie & 240 & 30.0 \\
\hline Sauniatu & 50 & 1.5 \\
\hline Lalo-Tanu 33kV tie & 260 & 26.0 \\
\hline East Coast & 200 & 10.0 \\
\hline Beach Rd & 200 & 10.0 \\
\hline Tanu-Fulu 33kV tie & 284 & 120.0 \\
\hline Alaoa & 120 & 10.0 \\
\hline Alaoa-FOF 22kV tie & 80 & 20.0 \\
\hline Hospital & 200 & 10.0 \\
\hline Palisi & 200 & 20.0 \\
\hline Vailtele & 200 & 20.0 \\
\hline Industrial & 200 & 20.0 \\
\hline
\end{tabular}




\begin{tabular}{|l|c|c|}
\hline West Coast1 & 200 & 20.0 \\
\hline Lefaga & 180 & 20.0 \\
\hline West Coast2 22kV tie & 200 & 20.0 \\
\hline Fiaga 33kV OH/ UG & 100 & 20.0 \\
\hline
\end{tabular}

We ran computer simulations and results were analyzed as follows:

- Comparison of island-mode and interlock mode using Fuluasou sub since it has no generators but a PV system that supports the Industrial Zone Feeder.

- $\quad$ Application of fault on load bus and swing bus then comparison of fault currents in each bus on four instances: L-G, LL-G, LLL-G, 3-phase fault

- Application of AC arc flash on Bus 10 which hosts the two feeders with the high capacities.

Island-mode entails the isolation of the Fuluasou substation by opening circuit breakers of transmission lines to other substations. Only Fiaga sub circuit breaker is closed since it is the sole power supply for Fuluasou sub. L-G fault was applied on phase $\mathrm{C}$ for comparison. The purpose of the simulation was to explore grid stability for isolated systems which are common for economically disadvantaged nations or private utility companies.

Fault was applied to load bus 15 and swing bus 1 to compare the amount of fault current on each buses. The load bus hosted the Vailtele feeder line which many customers are connected to in Upolu. The swing bus in the Fiaga substation has 6 generators connected in parallel.

Figure 10 shows the bus fault currents for the load bus (bus 15) and the swing bus (bus 1).

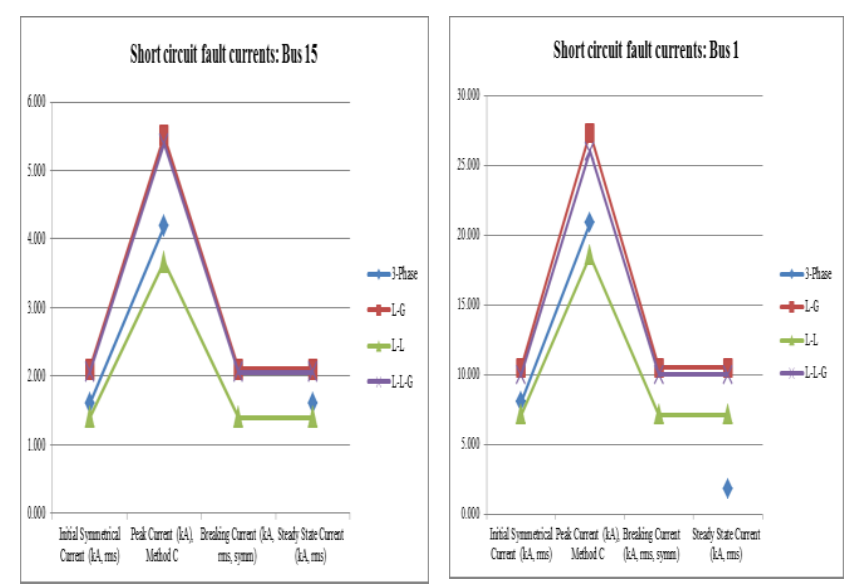

Fig. 10 Bus fault currents
Simulation results for fault currents in the load bus show that L-G and LL-G currents are equal with the peak fault current at $5.7 \mathrm{kA}, 3$-phase fault peak current at $4.3 \mathrm{kA}$ and $\mathrm{L}-\mathrm{L}$ peak current at $3.9 \mathrm{kA}$. Results for the swing bus show that L-G peak current is the highest at $28 \mathrm{kA}$, LL-G at $26 \mathrm{kA}$, 3 phase at $22 \mathrm{kA}$ and $\mathrm{L}-\mathrm{L}$ fault peak current at $18 \mathrm{kA}$. From the obtained result it seen that the L-G and the LL-G fault that are considered the most critical on load and swing buses. These faults occur mostly as a result of storm damages or lightning where the lines come into physical contact with each other or the ground. A summary of the paper is presented next.

\section{Conclusion}

In this paper, we have successfully implemented and conducted fault analysis for the EPC power grid. Various electrical power system fault models were considered. Comparison of faults in three-phase, line to line, line to ground, double line to ground as carried out yields that the most severe fault by interpretation of behaviors is the line to ground fault.

As a final remark, the increase in demands for electrical power needs monitoring and better management to avoid interruption in power delivery as it can be a big disturbance to consumers as well as it is depraving to economic development.

\section{List of Acronyms}

EPC Electric Power Corporation

GIS Geographic Information System

LV Low Voltage

HV High Voltage

ETAP Electronic Transient and Analysis

SG Synchronous Generator

L-G Line-to-ground

LL-G Double line-to-ground

L-L Line-to-line

PPE Personal Protective Equipment

LM1 Lalomauga Generator 1 (Hydro)

LM2 Lalomauga Generator 2 (Hydro)

TaF Taelefaga

FOF Fale 'Ole Fe'e 


\section{References:}

[1] Power Systems [Online]. Available: https://www.ece.ncsu.edu/research/pes/ps.

[2] H. Shi and X. Zhou, Stability Analysis on Power System with Large Power Source, Energy and Power Engineering, pp. 517-521, 2013.

[3] J. Santamaria, Analysis of Power Systems Under Faults Conditions, California State University, Sacramento, 2011.

[4] S. Sanguri and L. Stonecypher, Bright Hub Engineering, 2010. [Online]. Available:

[5] http://www.brighthubengineering.com/powergeneration-distribution/71084-how-asubstation-works/.

[6] R. Lucas, Power System Analysis, 2005.

[7] T. Gonen, Electric Power Trnasmission System Engineering, Analysis and Design, Crc Press Tayor and Francis Group.

[8] H. Sadaat, Power System Analysis, Milwaukee School of Engineering, WBC McGraw-Hill.

[9] UserGIS Map Infor, Electric Power Corporation of Samoa.

[10] J. Schlabbach, Calculation of Short Circuit in A.C Three-Phase HV-Systems, in Engineering 360, IEEE GlobalSpec, 2005.

[11] S. McFayden, Types of Fault, My Electrical Engineering, July 2012. [Online]. Available: http://myelectrical.com/notes/entryid/192/faultcalculations-introduction.

[12] Symmetrical Fault Current Calculations.

[13] J. Kauwale, Transmission and Distribution Technical Study Guide, Engineering Pro Guides, 2016.

[14] ETAP, [Online]. Available: https://etap.com/company/about-us. 